\title{
SOSIALISASI SADAR ARSIP DAN PENYELAMATAN MEMORI MELALUI FILM
}

\author{
Fitria Agustina, S.IP.
}

\begin{abstract}
Abstrak
Arsip sudah semakin dikenal oleh masyarakat. Akan tetapi pengenalan itu hanya sebatas dipermukaan saja. Hal ini disebabkan belum maksimalnya sosialisasi kearsipan yang dilakukan pemerintah, khususnya lembaga pembina kearsipan. Sosialisasi yang sudah dilaksanakan belum menjangkau setiap lapisan masyarakat, kebanyakan hanya kepada orang yang berprofesi dalam dunia kearsipan.

Untuk dapat mencapai tujuan sosialisasi sesuai yang diharapakan, salah satu media yang dapat digunakan adalah melalui film cerita. Film cerita dapat dengan mudah menyampaikan pesan kepada para penonton. Beberapa film Indonesia yang ditayangkan pada tahun 2016 telah menampilkan pesan terkait dengan arsip, seperti film Ada Apa Dengan Cinta 2 (AADC 2), Sabtu Bersama Bapak, dan Surat dari Praha.

Untuk ke depannya, pemerintah seharusnya bisa menangkap peluang bekerja sama dengan insan perfilman untuk mencipatakan film berkualitas yang dapat mendidik bangsa, terutama untuk mewujudkan masyarakat sadar arsip.
\end{abstract}

kata kunci: sosialisasi kearsipan, sadar arsip, memori, film

\section{A. Pendahuluan}

Dewasa ini, arsip sudah semakin dikenal oleh masyarakat. Arsip memiliki nilai informasi yang sangat tinggi sebagai memori masa lalu sekaligus bukti sejarah yang mampu memberi inspirasi dan sumber pengetahuan.
Kesadaran dan perhatian akan pentingnya nilai arsip inilah yang dijadikan tonggak utama dalam rangka mewujudkan masyarakat tertib arsip yang selanjutnya secara otomatis akan menjaga memori, baik memori individu maupun memori kolektif.

\footnotetext{
Arsiparis Arsip UGM
} 
Membangun masyarakat sadar arsip harus dimulai semenjak arsip-arsip itu diciptakan oleh seseorang ataupun instansi sampai arsip-arsip tersebut disimpan di lembaga kearsipan yang bertanggung jawab untuk menjaga dan merawatnya. Kesadaran ini harus dibangun pada pribadi setiap individu. Hal yang perlu diingat bahwa sadar arsip bukan hanya monopoli arsiparis dan petugas kearsipan sebagai pengelola dan pengendali arsip saja, tapi juga tanggung jawab kita semua.

Lembaga kearsipan, sebagai lembaga yang bertugas melakukan pembinaan kearsipan sudah saatnya melakukan gebrakan baru untuk lebih mengenalkan arsip kepada masyarakat. Arsip memang sudah lebih dikenal oleh masyarakat, tapi pengenalan arsip masih di permukaannya saja. Padahal secara tidak langsung, arsip senantiasa berada di sekeliling kita. Misalnya saja arsip pribadi seperti KTP, Kartu Keluarga, ijazah, dll. Hal ini disebabkan belum maksimalnya sosialisasi kearsipan di masyarakat.

Sosialisasi kearsipan dapat dilaksanakan dengan berbagai cara melalui pameran arsip, penyuluhan, media massa (radio, televisi, dan surat kabar), film, dan lain-lain. Selama ini sosialisasi arsip sudah dilakukan dengan berbagai cara tersebut. Akan tetapi kecenderungan lebih banyak hanya di kalangan profesi kearsipan seperti arsiparis, pengelola arsip, dan pemerhati arsip. Sosialisasi ini belum sepenuhnya merambah ke semua lapisan masyarakat dan semua umur. Padahal, pengenalan arsip sejak dini amatlah penting, terlebih kepada generasi muda.

Tidak hanya pelajar, mahasiswapun masih banyak yang belum mengenal arsip. Sosialisasi yang dapat menyentuh generasi muda seperti pelajar dan mahasiswa ini bisa dilakukan melalui media yang saat ini digemari oleh mereka. Salah 
satunya adalah melalui film cerita.

\section{B. Kerangka Pemikiran}

Dalam Kamus Besar Bahasa Indonesia (KBBI) online, pengertian sosialisasi adalah 1 . usaha untuk mengubah milik perseorangan menjadi milik umum (milik negara); 2. proses belajar seorang anggota masyarakat untuk mengenal dan menghayati kebudayaan masyarakat dalam lingkungannya; 3 . upaya memasyarakatkan sesuatu sehingga menjadi dikenal, dipahami, dihayati oleh masyarakat; pemasyarakatan. ${ }^{2}$

Apabila dihubungkan dengan dunia kearsipan, sosialisasi a r s i p a a l a h u a y a memasyarakatkan arsip sehingga menjadi dikenal, dipahami, dan dihayati oleh masyarakat. Tujuan dari sosialisasi arsip adalah untuk mengenalkan, menambah wawasan, dan menumbuhkan kesadaran akan arti pentingnya arsip.

Berdasarkan Undang-
Undang Nomor 33 Tahun 2009 tentang Perfilman, pengertian film adalah karya seni budaya yang merupakan pranata sosial dan media komunikasi massa yang dibuat berdasarkan kaidah sinematografi dengan atau tanpa suara dan dapat dipertunjukkan. Sedangkan perfilman adalah berbagai hal yang berhubungan dengan film.

Pada pasal 3 disebutkan bahwa tujuan dari perfilman adalah: a. terbinanya akhlak mulia; b. terwujudnya kecerdasan kehidupan bangsa; c . terpeliharanya persatuan dan kesatuan bangsa; d. meningkatnya harkat dan martabat bangsa; e. berkembangnya dan lestarinya nilai budaya bangsa; f. dikenalnya budaya bangsa oleh dunia internasional; g. meningkatnya kesejahteraan masyarakat; dan h. berkembangnya film berbasis budaya bangsa yang hidup dan berkelanjutan. Selanjutnya pada pasal 4 disebutkan perfilman mempunyai fungsi: a. budaya; $b$.

\footnotetext{
${ }^{2}$ http://kbbi.web.id/memori diakses tanggal 27 Oktober 2016.
} 
pendidikan; c. hiburan; d. informasi; e. pendorong karya kreatif; dan f. ekonomi.

Bertumpu pada UndangUndang Nomor 33 tahun 2009 tentang Perfilman tersebut, film dapat dijadikan sarana yang berfungsi sebagai hiburan sekaligus pendidikan bagi masyarakat untuk mewujudkan kecerdasan kehidupan bangsa. Kaitannya dengan arsip, film sebagai hiburan sekaligus dapat dijadikan sarana untuk menyosialisasikan arsip kepada masyarakat yaitu untuk mewujudkan masyarakat sadar arsip dan masyarakat yang senantiasa menjaga memori, baik memori individu maupun memori kolektif.

Film sebagai salah satu bentuk media massa juga dapat dilihat sebagai sesuatu yang memiliki dampak pada penonton. Hal ini sesuai dengan yang dikemukakan oleh Rasit, Rosmawati Mohamad, dkk.,

Film as one of the forms of mass media is also seen as something that has impact on the audience. The conveying of the communication message in every film production also helps film producers bring forward certain messages intended to be delivered to the film audience. Therefore, film is not only elevated as an aspect of art but most important, it is also the medium of conveying effective messages that can be propagated among the society. This was put forward by A. Razak (2004: 65), stating that film should not be seen from the perspective of art only. Film is a medium of communication for educating the society by conveying a certain message to the public. Moreover, Jowett and Linton (1985: 16) confirmed that the study of film is not just a study of art but the perspective of film also acts as a mass communication, playing a role as a mass-mediated culture in society. $^{3}$

Sejalan dengan hal tersebut, Joseph Goebbles, menyebutkan bahwa film adalah salah satu dari

${ }^{3}$ Rasit, Rosmawati Mohamad, dkk., "Film as a Medium of Communication for Dacwah: Analysis of Religious Elements in Selected Malay Films/Filem sebagai Saluran Komunikasi Da'wah: Analisis Unsur Keagamaan dalam Filem Melayu yang Dipilih", http://search.proquest.com/docview/1012196428? pq-origsite $=$ summon, diakses tanggal 30 Oktober 2016. 
media modern dan berjangkauan luas yang dapat mempengaruhi massa. ${ }^{4}$

Berdasarkan pemikiran tersebut, dapat disimpulkan bahwa f i $1 \mathrm{~m} \quad \mathrm{~s}$ e j a k a w a 1 perkembangannyapun sudah digunakan sebagai sarana untuk mempengaruhi massa/penonton. Hal ini dapat menjadi dasar pemikiran bahwa film di Indonesia pun dapat dijadikan sarana edukasi untuk menambah pengetahuan penonton dengan segala sesuatu yang berkaitan dengan dunia kearsipan.

\section{Pembahasan}

Setiap orang pasti memiliki arsip, bahkan sejak manusia lahir hingga meninggal. Arsip pribadi yang tercipta secara perseorangan, maupun arsip sebagai warisan dari para pendahulu yang dijadikan sebagai memori. Dalam KBBI online, memori berarti kesadaran akan pengalaman masa lampau yang hidup kembali; ingatan. Kenangan masa lalu (sejarah) berguna untuk menghadapi masa yang akan datang agar tidak terperosok dalam lubang yang sama. Sejarah adalah jejak masa lalu yang harus dijaga dan dirawat keberadaannya. Menumbuhkan kecintaan pada jejak jejak masa lalu tentunya akan menumbuhkan juga rasa cinta kita terhadap negara kita tercinta.

Dalam Deklarasi Universal tentang Kearsipan disebutkan:

Arsip merekam keputusan, tindakan, dan memori. Arsip merupakan warisan yang unik dan tidak tergantikan melintasi satu generasi ke generasi berikutnya. Arsip dikelola sejak penciptaan untuk melestarikan nilai guna dan peruntukannya. Arsip merupakan sumber informasi yang sah dalam mendukung kegiatan administrasi yang akuntabel dan transparan. Arsip memainkan peran penting dalam pengembangan masyarakat dengan cara menjaga dan membantu memori individu dan

${ }^{4}$ Budi Irwanto, "Film Propaganda: Ikonografi Kekuasaan", Jurnal Ilmu Sosial dan politik, Vol. 8, No. 1, Juli 2014, halaman 2.

${ }^{5}$ http://kbbi.web.id/memori diakses tanggal 12 Juli 2016 
kolektif. Keterbukaan akses arsip memperkaya pengetahuan kita mengenai masyarakat, mendorong demokrasi, melindungi hak warga negara, dan meningkatkan kualitas hidup. ${ }^{6}$

Berdasarkan deklarasi tersebut, diketahui bahwa peran penting arsip dalam pengembangan masyarakat adalah dengan cara menjaga dan membantu memori individu dan kolektif. Bagi individu, arsip merekam kehidupan sejak lahir hingga meninggal, seperti surat kelahiran, akta kelahiran, ijazah, surat nikah, dan surat kematian. Bagi kolektif atau organisasi, arsip merekam perjalanan dan perkembangan organisasi.

Untuk memelihara memori individu atau memori kolektif, perlu adanya kesadaran setiap orang untuk memahami pentingnya arsip dan pentingnya mengelola arsip. Untuk mencapai hal tersebut diperlukan sosialisasi kearsipan. Sosialisasi kearsipan tidak hanya dilakukan oleh arsiparis di lembaga kearsipan saja.
Akan tetapi, setiap orang dengan profesi yang digeluti bisa berperan serta dalam sosialisasi ini dengan cara yang sesuai dengan profesinya.

Saat ini, film menjadi sarana efektif yang dapat digunakan dalam sosialisasi kearsipan. Bukan hanya film dokumenter yang cenderung membosankan karena kurang menarik dan "hanya itu-itu saja", tapi melalui film cerita yang dapat ditonton oleh semua orang.

Mengapa film cerita dapat dijadikan media yang efektif dalam sosialisasi kearsipan? Pesan yang ada dalam film dapat berupa apa saja tergantung dari misi film tersebut. Umumnya, sebuah film dapat mencakup beberapa pesan sekaligus seperti pesan hiburan, pendidikan, dan informasi. Penyampaian pesan dalam film menggunakan suara, perkataan, percakapan, gerak tubuh, dan sebagainya.

Film juga dapat dijadikan media komunikasi yang ampuh

${ }^{6}$ http://www.ica.org/sites/default/files/UDA_2012_web_ID.pdf diakses 14 Juli 2016 
untuk mempengaruhi massa, karena sifatnya yang audio visual, yaitu gambar dan suara yang hidup. Gambar dan suara dalam film mampu bercerita banyak dalam waktu singkat. Ketika menonton film penonton seakan-akan dapat menembus ruang dan waktu yang dapat menceritakan kehidupan dan bahkan dapat mempengaruhi penonton. Selain itu penyajian cerita yang merupakan cerminan dari kehidupan nyata membuat penonton ikut terbawa dalam arus cerita dan membuatnya merasa memiliki kesamaan kondisi, sehingga penyampaian pesan akan mudah ditangkap dan dipahami.

Dewasa ini perkembangan dunia perfilman di Indonesia semakin meningkat. Film banyak diproduksi dengan berbagai genre seperti sejarah, biografi, drama, komedi, misteri, dan lain sebagainya. Kondisi seperti ini merupakan peluang bagi lembaga kearsipan atau pemerhati arsip untuk berperan serta dalam pembuatan film yang ingin menyampaikan pesan terkait dengan arsip.

Beberapa film Indonesia mungkin tidak sengaja telah mengenalkan "arsip" kepada masyarakat. Film Ada Apa Dengan Cinta 2 (AADC 2) yang telah menjadi box office dan menyedot 3,6 juta penonton. Dalam film ini ada percakapan penting yang berkaitan dengan arsip. Cinta, tokoh utama film ini mengatakan “..dia itu udah kayak arsip!” dan tanggapan Milly, "Kalau arsip berarti masih lo simpen dong!" Dari percakapan singkat tersebut secara tidak disadari film AADC 2 telah mengenalkan arsip. Bahwa arsip harus disimpan. Setiap kalimat yang diucapkan dalam film tersebut akan terus diingat oleh penonton yang menggemari film atau pemeran dalam AADC 2 . Apabila percakapan itu hanya dilakukan oleh arsiparis, akan menjadi hal yang biasa dan tidak berkesan. Tetapi bila diucapkan dalam film oleh si tokoh utama, tentunya akan mendapat perhatian 
dan kesan yang mendalam bagi para penonton. Penonton akan terus mengingat perkataan atau pesan yang ada dalam film tersebut.

Dalam film lain, "Sabtu Bersama Bapak", jika diamati dengan seksama, objek utama yang diangkat adalah arsip. Lain halnya dengan AADC 2 yang melontarkan pesan terkait arsip dalam kalimat, di Sabtu Bersama Bapak ini yang digunakan adalah arsip video. Video yang berisi pesan-pesan yang direkam oleh seorang bapak yang ditujukan kepada istri dan anak-anaknya hanya dapat ditonton setiap hari Sabtu. Saat video direkam, anak-anak yang saat itu masih kecil dan hingga dewasa video tersebut masih disimpan dan beberapa sudah dialihmediakan ke dalam flash disk.

Jika penonton jeli dan kritis akan menimbulkan tanda tanya. Bagaimana cara ibu tersebut menyimpan video tersebut agar tetap terpelihara, baik fisik maupun informasinya sehingga setelah bertahun-tahun berlalu video peninggalan bapak dapat terus diputar? Bagaimana seandainya video tersebut ada yang hilang atau rusak? Meskipun tidak ada adegan yang jelas tentang cara menyimpan dan memelihara arsip, setidaknya dari film tersebut, penonton mendapat gambaran tentang arsip video dan alih medianya. Mengingat kondisi video tersebut yang masih tetap bagus, dapat diputar dan dialihmediakan meskipun sudah tua, secara tidak sengaja memberikan pendidikan kepada penonton bahwa arsip tidak hanya disimpan, tetapi juga harus dipelihara agar kenangan yang terkandung di dalamnya tetap terjaga.

Arsip jenis lain yang dijadikan objek dalam film berupa surat adalah "Surat dari Praha". Film tersebut mengisahkan perjalanan seorang wanita muda bernama Laras yang mengantarkan sebuah kotak dan sepucuk surat yang ditulis ibunya (Sulastri) untuk Jaya di Praha, Republik Ceko. Kotak tersebut ternyata berisi surat 
yang ditulis oleh Jaya pada tahun 1970-an, dan saat ini masih terjaga dan terpelihara baik fisik, maupun informasinya.

Tiga film yang dirilis pada tahun 2016 ini, sudah banyak memberikan informasi, atau sosialisasi bahwa arsip itu penting, harus disimpan, dan dipelihara agar memori yang terkandung di dalamnya dapat terus terjaga. Apabila dalam setiap film yang ditayangkan disisipi pesan-pesan yang berkaitan dengan arsip, entah itu hanya sebuah kata, dialog, atau menampilkan bentuk arsip, akan sangat membantu pemerintah dalam mengenalkan arsip kepada masyarakat terutama bagi para remaja. Dengan menggunakan film cerita akan memudahkan tujuan sosialisasi kearsipan dapat tercapai.

Profesi yang berkaitan dengan film inilah yang berperan sangat penting dalam mencapai tujuan masyarakat sadar arsip melalui sosialisasi yang dilakukan menggunakan media film.
Sosialisasi menggunakan media film ini hanya salah satu cara yang dapat dilakukan oleh pekerja seni maupun oleh pemerintah yang bekerja sama dalam pembuatan film. Masih banyak cara yang dapat dilakukan baik oleh individu maupun oleh pemerintah untuk menciptakan masyarakat sadar arsip.

\section{Penutup}

Arsip sudah semakin dikenal oleh masyarakat. Akan tetapi hanya sebatas dipermukaan saja. Hal ini disebabkan belum maksimalnya sosialisasi kearsipan oleh lembaga kearsipan yang bertugas untuk melakukan pembinaan. Sosialisasi yang sudah dilaksanakan belum mencakup setiap lapisan masyarakat, kebanyakan hanya kepada profesi yang terkait dalam dunia kearsipan.

Untuk dapat mencapai tujuan sosialisasi sesuai yang diharapakan, salah satu media yang dapat digunakan adalah melalui 
film cerita. Film cerita dapat dengan mudah menyampaikan pesan yang termuat dalam film kepada para penonton. Beberapa film Indonesia yang ditayangkan pada tahun 2016 telah menampilkan pesan terkait dengan arsip.

Hal tersebut seharusnya dapat menggugah pemerintah khususnya lembaga kearsipan baik pusat maupun daerah untuk menangkap peluang bekerja sama dengan insan perfilman dalam rangka menciptakan film yang berkualitas yang dapat memberikan hiburan, pendidikan, dan informasi terkait dengan tujuan sosialisasi

\section{DAFTAR PUSTAKA}

Undang-Undang Republik Indonesia Nomor 33 Tahun 2009 tentang Perfilman.

Irwanto, Budi, "Film Propaganda: Ikonografi Kekuasaan", Jurnal Ilmu Sosial dan Politik, Vol. 8, No. 1, Juli 2014, halaman 2 . kearsipan yaitu menuju masyarakat sadar arsip. Sadar arsip akan mewujudkan tertib arsip yang selanjutnya pelaksanaannya dapat menjaga memori individu maupun memori kolektif. Dengan demikian, adanya arsip yang terselamatkan akan menjaga memori generasi muda untuk mengetahui dan memahami sejarah perjalanan bangsa. Hal ini penting sebab arsip sangat dekat dengan pemahaman sejarah, menjaga memori, bangsa, dan negara yang pada akhirnya menjadi pemersatu bangsa dalam lingkup Negara Kesatuan Republik Indonesia (NKRI).

Rasit, Rosmawati Mohamad, dkk., "Film as a Medium of Communication for Dacwah: Analysis of Religious Elements in Selected Malay Films/Filem sebagai Saluran Komunikasi Da'wah: Analisis Unsur Keagamaan dalam Filem Melayu yang Dipilih", http://search.proquest.com/ docview/1012196428? pq- 
origsite $=$ summon, diakses tanggal 30 Oktober 2016.

http://kbbi.web.id/memori diakses tanggal 12 Juli 2016.

http://kbbi.web.id/film diakses tanggal 27 Oktober 2016. http://kbbi.web.id/sosialisasi diakses tanggal 27 Oktober 2016.

http://www.ica.org/sites/default/files/ UDA_2012-web_ID.pdf diakses tgl 14 Juli 2016. 